

\title{
Editorial
}

\section{Time to improve pre-hospital care in developing countries}

\author{
Malcolm Boyle PhD, Editor and Academic Lead in Paramedic Education ${ }^{1,2}$; Jaime Wallis BEH, Lecturer2; Suryanto
} M.Nurs, Lecturer and PhD candidate 3,4

\author{
Affiliation: \\ ${ }^{1}$ Australasian Journal of Paramedicine \\ ${ }^{2}$ Griffith University, School of Medicine, Queensland \\ ${ }^{3}$ Brawijaya University, School of Nursing, Malang, Indonesia \\ ${ }^{4}$ Monash University, School of Nursing and Midwifery, Victoria
}

Developing countries such as Indonesia do not have well established emergency medical service (EMS) systems like Australia, New Zealand, the United Kingdom and the United States of America. However, a considerable amount of research, development and funding are paving the way for developing countries to enhance and evolve their systems to suit their needs.

The Health Ministry in Indonesia recently announced the introduction of a 119 emergency number for Indonesians to activate the response of an ambulance to an emergency medical or trauma situation (1). In spite of this, there is no guarantee that an ambulance will arrive in a timely manner due to a multitude of reasons. There are potential issues with the redirection of the emergency call from the call centre to the appropriate hospital to deal with the emergency situation. Another issue is the lack of infrastructure and resources in which to manage the emergency response.

The majority of ambulances in Indonesia are staffed by emergency nurses from the hospital emergency department (ED) or nursing staff from the Puskesmas (a community health clinic). The staffing of the ambulance varies from one non-medical qualified driver and two nurses to one driver and one nurse. These ED and Puskesmas nurses have varying qualifications and skill levels.

The equipping of ambulances varies considerably between the ambulances based out of hospitals and the Puskesmas ambulance. Generally the Puskesmas ambulance may have a stretcher and little else whilst an ambulance from a major hospital could contain basic equipment including a monitor/defibrillator, spine board and an assortment of medications. These resources are clearly limited when compared to nearby neighbours Australia and New Zealand's pre-hospital resources. The other aspect that is glaringly different is that there is no dedicated pre-hospital care education for those nurses who staff the ambulances.

Thus far the Australian Department of Foreign Affairs and Trade through the Australia Indonesia Institute has funded two projects to help educate the nurses that staff the ambulances. A pilot program is currently underway in Malang, East Java where staff from the School of Medicine at Griffith University in conjunction with Brawijaya University are conducting the pilot program with assistance from the School of Nursing and Midwifery at Monash University. The aim of the project is for Griffith University staff to impart and share their knowledge and experience of Australian pre-hospital care and management with Brawijaya University emergency nursing staff. The plan is that the newly trained university staff will take this knowledge and application of the Ambulance Nurse program and incorporate it into their Master of Nursing (Emergency Nursing) course.

More educational initiatives, such as this collaborative train-the-trainer approach, are needed in developing countries. This shared knowledge empowers and educates people in their own country so they can develop their pre-hospital emergency care services which in turn will result in better health outcomes for their communities. 
Dr Mal Boyle

Editor

Australasian Journal of Paramedicine

Jaime Wallis

Griffith University, School of Medicine

\section{Suryanto}

Brawijaya University, School of Nursing

Monash University, School of Nursing and Midwifery

\section{Reference}

1. Dzulfiqar F, Riza B. Health Ministry Launches Emergency Service 119. TempoCo. 1st July 2016. Available at: http:// en.tempo.co/read/news/2016/07/01/055784833/Health-Ministry-Launches-Emergency-Service-119 